\title{
PENYALAHGUNAAN AMPHETAMIN PADA ATLET TINJU
}

\author{
Hegen Dadang Prayoga ${ }^{1}$ \\ Novri Asri ${ }^{2}$ \\ Universitas Islam Kalimantan Muhammad Arsyad Al Banjari \\ hegen.dadang.prayoga@gmail.com
}

\begin{abstract}
ABSTRAK
Penyalahgunaan obat-obatan saat ini telah menjadi masalah serius, dan mengenai banyak kalangan, tanpa peduli akan status ekonomi seseorang. Sebagian timbul dari segi keingintahuan, sebagian dari segi mudah mendapatkan, atau khusus karena faktor psikologis seseorang atau juga dari sisi budaya yang mulai membuat keberadaan obat ini 'biasa' dikonsumsi. Atlet ataupun pembina olahraga seringkali menginginkan adanya prestasi yang baik dalam waktu singkat padahal pembinaan prestasi merupakan proses yang memerlukan waktu tertentu. Mereka bisa saja menempuh jalan pintas penuh resiko dengan berbagai cara, di antaranya dengan mengkosumsi obat yang berlebihan. Ada beberapa faktor yang menyebabkan timbulnya doping dalam dunia olahraga. Seorang atlet melakukan doping pada umumnya diawali dari aspek alamiah para individu atlet maupun pelatihnya sendiri. Artinya, secara alami atau naluri setiap manusia, siapapun, kapanpun, dan di manapun, termasuk para pelaku olahraga (atlet dan pelatih) berpotensi untuk melakukan pelanggaran, ditambah lagi apabila lingkungan memberi kesempatan dan peluang bagi mereka untuk melakukan pelanggaran tersebut
\end{abstract}

Kata Kunci: Amphetamin, Atlet, Tinju

\begin{abstract}
Drug abuse has now become a serious problem, and has many people, regardless of one's economic status. Some arise in terms of curiosity, some in terms of easy to get, or specifically because of someone's psychological factors or also from the cultural side that starts to make the existence of this drug 'normal' consumed. Athletes or sports coaches often want a good achievement in a short time even though achievement coaching is a process that requires a certain time. They can just take a risky shortcut in various ways, including by consuming excessive medication. There are several factors that cause doping in the world of sports. An athlete doing doping generally starts from the natural aspects of the individual athletes and their own coaches. That is, naturally or instinctively every human being, anyone, anytime, anywhere, including sports people (athletes and coaches) has the potential to commit violations, plus if the environment provides opportunities and opportunities for them to commit these violations
\end{abstract}

Keywords: Amphetamin, Athtlete, Boxing

Dipublikasikan Oleh :

UPT Publikasi dan Pengelolaan Jurnal

Universitas Islam Kalimantan Muhammad Arsyad Al-Banjari Banjarmasin 


\section{PENDAHULUAN}

Penyalahgunaan obat-obatan saat ini telah menjadi masalah serius, dan mengenai banyak kalangan, tanpa peduli akan status ekonomi seseorang. Sebagian timbul dari segi keingintahuan, sebagian dari segi mudah mendapatkan, atau khusus karena faktor psikologis seseorang atau juga dari sisi budaya yang mulai membuat keberadaan obat ini 'biasa' dikonsumsi.

Secara harfiah menurut Kamus Besar Bahasa Indonesia, arti kata "penyalahgunaan" adalah suatu proses, cara, perbuatan menyelewengkan. Sehingga pengertian penyalahgunaan obat adalah Penggunaan salah satu beberapa jenis obat yang dilakukan tanpa aturan kesehatan maupun secara berkala atau teratur sehingga menimbulkan gangguan kesehatan jasmani jiwa dan fungsi sosialnya (Departemen Pendidikan Nasional, 2007).

Atlet ataupun pembina olahraga seringkali menginginkan adanya prestasi yang baik dalam waktu singkat padahal pembinaan prestasi merupakan proses yang memerlukan waktu tertentu. Mereka bisa saja menempuh jalan pintas penuh resiko dengan berbagai cara, di antaranya dengan mengkosumsi obat yang berlebihan. Tindakan ini sangat berbahaya karena berakibat fatal seperti kasus kematian atlet (Moeloek, 2005).

Ada beberapa faktor yang menyebabkan timbulnya doping dalam dunia olahraga. Seorang atlet melakukan doping pada umumnya diawali dari aspek alamiah para individu atlet maupun pelatihnya sendiri. Artinya, secara alami atau naluri setiap manusia, siapapun, kapanpun, dan di manapun, termasuk para pelaku olahraga (atlet dan pelatih) berpotensi untuk melakukan pelanggaran, ditambah lagi apabila lingkungan memberi kesempatan dan peluang bagi mereka untuk melakukan pelanggaran tersebut

Pengertian Doping itu sendiri adalah upaya meningkatkan prestasi dengan menggunakan zat atau metode yang dilarang dalam olahraga dan tidak terkait dengan indikasi medis. Selain obat, bentuk lain dari doping ialah doping darah, baik melalui transfusi darah maupun penggunaan hormon eritropoietin atau steroid anabolik tetrahidrogestrinon.

Berikut zat-zat Doping yang dikelompokkan kedalam 7 golongan: stimulan (amphetamine, caffein, cocain, aphedrine, dll), narkotik-analgesik (methadone, morphine, oxycodone,dll), androgenik (testosterone, balasterone, dll), anabolik non steroid (clenbuterol, zeranol, dll), penghalang beta (acebutotlol, atenolol, sotalol, dll), diuretika (acetazolamid, amiloride, chlormerodrin, dll) dan peptida hormon (rivokempoel, 2010).

Adanya zat-zat berbahaya dalam Doping, muncul kebijakan yang mengatur penggunaannya dan program tes Doping untuk memonitor. Hal ini dimaksudkan agar atlet-atlet tidak sembarangan dan bahkan terlalu sering dalam menggunakan Doping. Karena ditakutkan akan terjadi penyakit yang nantinya akan merugikan banyak pihak.

Obat stimulan, khususnya amphetamin, pertama kali digunakan dalam mengobati ganguan psikiatri. Pada tahun 1930-an karena efek nyata stimulasi SSP. Di masa lalu digunakan untuk mengatasi defresi dan obesitas, tetapi penggunaan obat tersebut tidak umum dalam praktik saat ini. Dekstroamphetamin (Dexedrine) telah disalahgunakan secara luas untuk menimbulkan rasa melayang (high) atau untuk terjaga selama periode waktu yang lama. Saat ini, penggunaan utama stimulan ialah untuk mengatasi ganguan hiperaktivitas/defisit perhatian (attention deficit/hyperactivity disoerder, ADHD) pada anak-anak dan remaja. Ganguan defisit perhatian sisa pada dewasa, dan narkolepsi (serangan rasa kantuk pada siang hari yang tidak diinginkan, tetapi tidak dapat diatasi yang menggangu kehidupan individu).

Seseorang yang kecanduan amphetamin dapat mengembangkan toleransi yang sangat cepat. Seseorang kecanduan amphetamin dapat memiliki episode psikotik saat menggunakan.

\section{METODE}

Metode penelitian yang digunakan adalah metode True Experimental Design yaitu jenis eksperimen yang dianggap betul dan baik karena dalam desain ini, penelitian dapat mengontrol semua variable luar yang mempengaruhi jalannya eksperimen. Menurut Sugiyono (2013 : 75), ciri utama dari True Experimental sampel yang digunakan untuk eksperimen maupun sebagai kelompok control diambil secara random dari populasi tertentu.

\section{HASIL DAN PEMBAHASAN}

Setelah dilakukan pengumpulan data dari tanggal 5 Juni 2012 sampai tanggal 16 juni 2012 dengan menggunakan lembar kuesioner terhadap sampel yaitu para atlet tinju yang berlatih di Wisma Antasari Banjamasin diperoleh sampel sebanyak 37 orang dengan spesifikasi sampel sebagai berikut :

Tabel 4.1 Spesifikasi Sampel Berdasarkan Umur Atlet di Wisma Antasari Banjamasin pada tanggal 5 Juni 2012 sampai tanggal 16 juni 2012

\begin{tabular}{|c|c|c|c|}
\hline No & Umur Atlet & Jumlah & Presentase \\
\hline 1 & $<20$ & 13 Orang & 35,1 \\
\hline
\end{tabular}

Dipublikasikan Oleh :

UPT Publikasi dan Pengelolaan Jurnal

Universitas Islam Kalimantan Muhammad Arsyad Al-Banjari Banjarmasin 


\begin{tabular}{|c|c|c|c|}
\hline 2 & $20-25$ & 18 Orang & 48,6 \\
\hline 3 & $>25$ & 6 Orang & 16,3 \\
\hline \multicolumn{2}{|r|}{ Jumlah Total } & 37 Orang & 100 \\
\hline
\end{tabular}

Pada tabel 4.1 di atas atlet tinju yang berlatih di Wisma Antasari Banjarmasin paling banyak pada umur 20 - 25 tahun sebanyak 18 orang $(48,6 \%)$.

4.2.2 Tabel spesifikasi sampel berdasarkan jenis kelamin

Tabel 4.2 Spesifikasi Sampel Berdasarkan Jenis Kelamin Atlet di Wisma Antasari Banjamasin pada tanggal 5 Juni 2012 sampai tanggal 16 juni 2012

\begin{tabular}{|c|c|c|c|}
\hline No & Jenis Kelamin Atlet & Jumlah & Presentase \\
\hline 1 & Laki-Laki & 32 Orang & 86,5 \\
\hline 2 & Perempuan & 5 Orang & 13,5 \\
\hline \multicolumn{2}{|c|}{ Jumlah Total } & 37 Orang & 100 \\
\hline
\end{tabular}

Pada tabel 4.2 di atas atlet tinju yang berlatih di Wisma Antasari Banjarmasin paling banyak berjenis kelamin laki-laki sebanyak 32 orang $(86,5 \%)$.

\subsubsection{Tabel spesifikasi sampel berdasarkan jenis pekerjaan atlet}

Tabel 4.3 Spesifikasi Sampel Berdasarkan Jenis Pekerjaan Atlet di Wisma Antasari Banjamasin pada tanggal 5 Juni 2012 sampai tanggal 16 juni 2012

\begin{tabular}{|c|c|c|c|}
\hline No & Jenis Pekerjaan Atlet & Jumlah & Presentase \\
\hline 1 & Siswa SMA & 7 Orang & 18,9 \\
\hline 2 & Mahasiswa & 14 Orang & 37,8 \\
\hline 3 & Wiraswata & 16 Orang & 43,3 \\
\hline \multicolumn{2}{|c|}{ Jumlah Total } & 37 Orang & 100 \\
\hline
\end{tabular}

Pada tabel 4.3 di atas atlet tinju yang berlatih di Wisma Antasari Banjarmasin paling banyak memiliki pekerjaan sebagai Wiraswasta sebanyak 16 orang $(43,3 \%)$.

4.2.4 Tabel data tabulasi silang berdasarkan umur atlet

Tabel 4.4 Data Tabulasi Silang Berdasarkan Umur Atlet di Wisma Antasari Banjamasin pada tanggal 5 Juni 2012 sampai tanggal 16 juni 2012

\begin{tabular}{|c|c|c|c|c|c|}
\hline \multirow{2}{*}{ No } & Umur Atlet & \multicolumn{2}{|c|}{ Meyalahgunakan } & \multicolumn{2}{c|}{ Tidak Menyalahgunakan } \\
\cline { 3 - 6 } & & Jumlah & $\%$ & Jumlah & $\%$ \\
\hline 1 & $<20$ & - & - & 13 Orang & 35,1 \\
\hline 2 & $20-25$ & 9 Orang & 24,3 & 9 Orang & 24,3 \\
\hline 3 & $>25$ & 5 Orang & 13,5 & 1 Orang & 2,8 \\
\hline \multicolumn{2}{|c|}{ Jumlah Total } & 14 Orang & 37,8 & 23 Orang & 62,2 \\
\hline
\end{tabular}

Pada tabel 4.4 di atas atlet tinju yang berlatih di Wisma Antasari Banjarmasin paling banyak melakukan penyalahgunaan pada umur 20 - 25 tahun sebanyak 9 orang $(24,3 \%)$.

4.2.5 Tabel data tabulasi silang berdasarkanjenis kelamin

Tabel 4.5 Data Tabulasi Silang Berdasarkan Jenis Kelamin Atlet di Wisma Antasari Banjamasin pada tanggal 5 Juni 2012 sampai tanggal 16 juni 2012

\begin{tabular}{|c|l|c|c|c|c|}
\hline \multirow{2}{*}{ No } & \multirow{2}{*}{ Jenis Kelamin } & \multicolumn{2}{|c|}{ Meyalahgunakan } & \multicolumn{2}{c|}{ Tidak Menyalahgunakan } \\
\cline { 3 - 6 } & & Jumlah & $\%$ & Jumlah & $\%$ \\
\hline 1 & Laki-laki & 14 Orang & 37,8 & 18 Orang & 48,7 \\
\hline 2 & Perempuan & - & - & 5 Orang & 13,5 \\
\hline \multicolumn{2}{|r}{ Jumlah Total } & 14 Orang & 37,8 & 23 Orang & 62,2 \\
\hline
\end{tabular}

\section{Dipublikasikan Oleh :}

UPT Publikasi dan Pengelolaan Jurnal

Universitas Islam Kalimantan Muhammad Arsyad Al-Banjari Banjarmasin 
Pada tabel 4.5 di atas atlet tinju yang berlatih di Wisma Antasari Banjarmasin paling banyak melakukan penyalahgunaan berjenis kelamin laki-laki sebanyak 14 orang $(37,8 \%)$.

4.2.6 Tabel distribusi frekuensi hasil penelitian

Tabel 4.6 Distribusi Frekuensi Hasil Penelitian di Wisma Antasari Banjamasin pada tanggal 5 Juni 2012 sampai tanggal 16 juni 2012

\begin{tabular}{|c|c|c|c|}
\hline No & $\begin{array}{c}\text { Penyalahgunaan amphetamin oleh } \\
\text { para atlet }\end{array}$ & Jumlah & Presentase \\
\hline 1 & Menyalahgunakan & 14 Orang & 37,8 \\
\hline 2 & Tidak Menyalahgunakan & 23 Orang & 62,2 \\
\hline \multicolumn{2}{|c}{ Jumlah Total } & 37 Orang & 100 \\
\hline
\end{tabular}

Tabel 4.6 menunjukan bahwa atlet tinju yang menggunakan amphetamin sebanyak 14 orang $(37,8 \%)$

4.2.7 Tabel jumlah jawaban responden per item pertanyaan

Tabel 4.7 Jumlah Jawaban Responden Per item Pertanyaan

\begin{tabular}{|c|c|c|c|}
\hline No & Pernyataan & $\begin{array}{l}\text { Jawaban } \\
\text { "YA" }\end{array}$ & $\begin{array}{l}\text { Jawaban } \\
\text { "TIDAK" }\end{array}$ \\
\hline 1 & $\begin{array}{l}\text { Anda pernah menggunakan obat- } \\
\text { obatan untuk menambah stamina }\end{array}$ & 20 Orang & 17 Orang \\
\hline 2 & $\begin{array}{l}\text { Anda pernah berpikiran melakukan } \\
\text { peningkatan penampilan dengan obat- } \\
\text { obatan tertentu }\end{array}$ & 16 Orang & 21 Orang \\
\hline 3 & $\begin{array}{l}\text { Menurut anda penggunaan obat-obatan } \\
\text { penambah stamina memiliki efek } \\
\text { samping }\end{array}$ & 24 Orang & 13 Orang \\
\hline 4 & $\begin{array}{l}\text { Anda mengetahui penggunaan obat } \\
\text { amphetamin dapat merangsang stamina }\end{array}$ & 20 Orang & 17 Orang \\
\hline 5 & $\begin{array}{l}\text { Anda pernah merasa frustasi karena } \\
\text { latian yang tak kunjung membuahkan } \\
\text { hasil }\end{array}$ & 26 Orang & 11 Orang \\
\hline 6 & $\begin{array}{l}\text { Menurut anda doping dapat dijadikan } \\
\text { sebagai metode meningkatkan prestasi } \\
\text { tanpa indikasi medis }\end{array}$ & 27 Orang & 10 Orang \\
\hline 7 & $\begin{array}{l}\text { Anda mengetahui jenis-jenis obat yang } \\
\text { termasuk doping }\end{array}$ & 14 Orang & 23 Orang \\
\hline 8 & Sebelum pertandingan ada tes doping & - & 37 Orang \\
\hline 9 & $\begin{array}{l}\text { Anda pernah mengunakan obat } \\
\text { amphetamin }\end{array}$ & 14 Orang & 23 Orang \\
\hline 10 & $\begin{array}{l}\text { Menurut anda seorang olahragawan } \\
\text { dituntut selalu tampil prima untuk } \\
\text { meraih impian }\end{array}$ & 37 Orang & - \\
\hline
\end{tabular}

Tabel 4.7 menunjukan banyaknya jumlah atlet yang beri jawaban "YA" dan "TIDAK" per item pertanyaan. Dari pernyataan nomer 9 dapat diketahui jumlah responden yang menjawab "YA" sebanyak 14 orang yang berarti telah menyalahgunakan amphetamin dan jumlah responden yang menjawab "TIDAK" sebanyak 23 orang yang berarti tidak menyalahgunakan amphetamin..

Hasil dan pembahasan berisi hasil-hasil temuan penelitian dan pembahasannya. Tuliskan temuan-temuan yang diperoleh dari hasil-hasil penelitian yang telah dilakukan dan harus ditunjang oleh data-data yang memadai.

Dipublikasikan Oleh :

UPT Publikasi dan Pengelolaan Jurnal

Universitas Islam Kalimantan Muhammad Arsyad Al-Banjari Banjarmasin 
Hasil-hasil penelitian dan temuan harus bisa menjawab pertanyaan atau hipotesis penelitian di bagian pendahuluan. Umumnya data-data hasil penelitian dapat dipaparkan menggunakan tabel. Contoh penggunaannya ditunjukkan pada tabel 1 .

Tabel 1. Contoh Penyajian Tabel

\begin{tabular}{lll}
\hline Komponen & Komponen & Komponen \\
\hline Data & Data & Data \\
Data & Data & Data \\
Data & Data & Data \\
\hline Total Data & Total Data & Total Data \\
\hline
\end{tabular}

Keterangan: Data; Data; Data

Khusus untuk artikel konseptual, cukup berisi pembahasan saja. Pemaparan tentang hasil tidak perlu dilakukan. Dengan demikian, untuk artikel konseptual, judul hanya bertuliskan 'Pembahasan'. Penulis dapat menyertakan gambar, grafik, atau diagram dalam pembahasan (juga bisa di bagian pendahuluan atau metode sesuai dengan kebutuhan penulis). Gambar 1 akan memberikan contoh penggunaan gambar dalam Riyadhoh : Jurnal Pendidikan Olahraga.

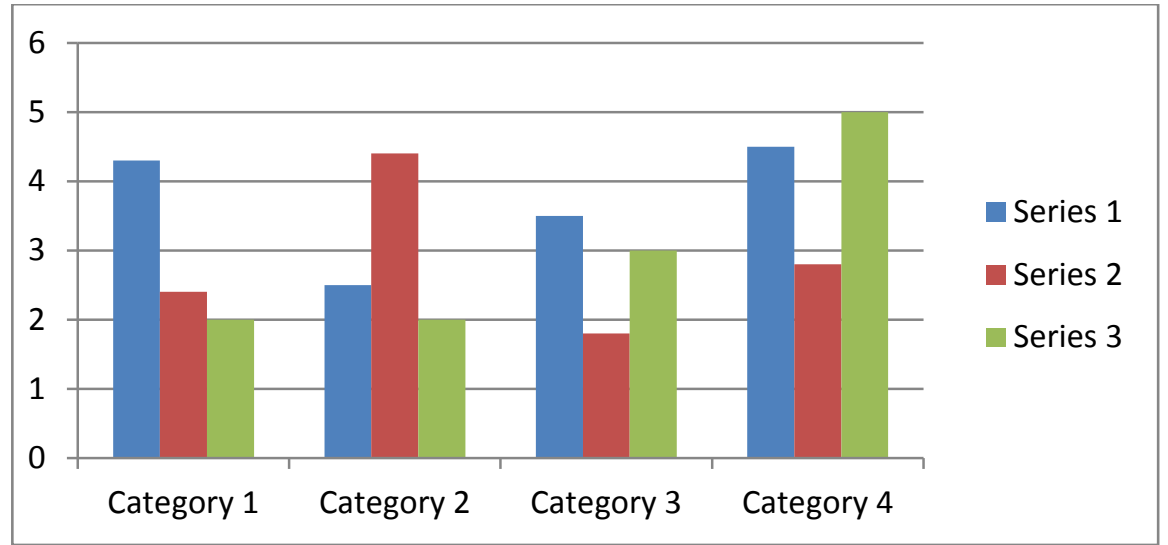

Gambar 1. Contoh Penyajian Diagram

Jika gambar berukuran kecil (memiliki perspektif vertikal lebih panjang dari pada horizontal atau seimbang), penulis perlu memuat gambar dengan format centered atau jika memungkinkan, dimasukkan dalam dua kolom. Contoh penyajiannya ditunjukkan pada Gambar 2.

\section{PENUTUP}

Berdasarkan hasil penelitian yang dilakukan di Wisma Antasari Banjarmasin tentang Gambaran Penyalahgunaan Amphetamin Oleh Para Atlet di Banjarmasin, maka dapat disimpulkan atlet tinju yang terbanyak tidak menggunakan amphetamin adalah 23 orang $(62,2 \%)$

\section{Saran}

-Saran Untuk Para Atlet :

a. Atlet diharapkan dapat mengetahui pengertian tentang efek buruk doping bagi tubuh dan mengetahui obatobat yang termasuk dalam jenis doping, sehingga kedepannya dapat menghindari penyalahgunaan obat.

b. Atlet diharapkan dapat menjaga penampilan supaya tampil prima dengan melakukan latihan tekun, teratur, terukur, sistematis dengan memanfaatkan teknologi terkini sejauh tidak melanggar ketentuan Induk Organisasi Olahraga dan tidak merugikan kesehatan.

\section{REFERENSI}

Anton Hermawan. 2012.Perbandingan ketepatan shoting kegawang menggunakan kaki bagian dalam dan kaki bagian luar pada tim sepak bola Banjarbaru. : Jurusan Pendidikan Olahraga dan Kesehatan FKIP UNLAM.

Brands, B., Sproule, B., and Marshman, J. (Eds.). (1998). Drugs \& Drug Abuse (3rd ed.). Addiction Research Foundation.

Dipublikasikan Oleh :

UPT Publikasi dan Pengelolaan Jurnal

Universitas Islam Kalimantan Muhammad Arsyad Al-Banjari Banjarmasin 
Dany H. Ludong. 2010. Pengaruh therapy community terhadap perbaikan kepribadian pengguna amphetamine. Balai Rehabilitasi BNN Baddoka.

Drug Enforcement Administration: Methamphetamine. Retrieved October 13, 2006, from

http://www.dea.gov/concern/meth_factsheet.html.

Edy D.P Duhe. 2012. Pengaruh pelatihan shadow boxing dengan metode interval Terhadap peningkatan Kapasitas aerobik maksimal (Studi Pada Petinju Sasana FIKK Universitas Negeri Gorontalo)

Harsuki. 2003. Perkembangan Olahraga Terkini. Kajian Para Pakar. Jakarta : Raja Grafindo Persada

Leo syahputra. 2008. Kamus besar bahasa indonesia: Lima bintang

KONI pusat. 1999. Pelaksanaan dan hasil program pelatihan Olahraga. Jakarta : KONI pusat

MEDLINEplus. (2004, November 8). Amphetamines (Systemic). Retrieved October 13, 2006, from http://medlineplus.nlm.nih.gov/medlineplus/druginfo/uspdi/202031.html.

Moeslim, Mochamad. 1968. Test Pengukuran Dalam Olahraga : Yogyakarta : Sekolah tinggi olahraga Yogyakarta.

Nurhasan .1998. Penilaian pembelajaran Penjaskes. Jakarta : Universitas Terbuka

Penyusunan norma kemampuan fisik atlet pencak silat se-diy (http://eprints.uny.ac.id/9069/1/1\%20$\% 2008602241061 . p d f)$

Sastropanoelar, S, 1992. Pendidikan Kesegaran Jasmani. Jakarta: Depdikbud.

Sifat dasar dan pengertian perbandingan http://padmimonang.wordpress. Com /2012/10/20/sifat-dasardan-pengertian-perbandingan-hukum/

Sudjana. 2005. Metode Statistika. Bandung : Tarsito.

Universitas pendidikan indonesia (http://repository.upi.edu/operator/ uplhttp://file.upi

.edu/Direktori/FPOK/JUR._PEND._OLAHRAGA/1965)

Dipublikasikan Oleh :

UPT Publikasi dan Pengelolaan Jurnal

Universitas Islam Kalimantan Muhammad Arsyad Al-Banjari Banjarmasin 